\title{
Hereditary Breast Cancer in Korea
}

\author{
Sung-Won Kim, MD, PhD, FACS*
}

Department of Surgery, Seoul National University College of Medicine, Seoul National University Bundang Hospital, Gyeonggi-do, Korea

\begin{abstract}
About $7 \%$ of all breast cancer (BC) cases result from a genetic predisposition, and approximately 1,000 patients develop hereditary $\mathrm{BC}(\mathrm{HBC})$ every year in Korea. $B R C A 1$ and $B R C A 2$ are the primary genes underlying $\mathrm{HBC}$. The average cumulative risks in BRCA1 mutation carriers at 70 years of age are 65\% (95\% confidence interval $44-78 \%)$ for BC and 39\% (18-54\%) for ovarian cancer (OC). The corresponding estimates for BRCA2 are $45 \%$ (31-56\%) and $11 \%(2.4-19 \%)$, respectively. The penetrance of $B R C A$ mutations is not the same between patients and can depend on factors such as race and birth-cohort. The Korean Hereditary Breast Cancer (KOHBRA) study is a large prospective nationwide study that includes 39 participating centers. Between May 2007 and May 2010, the first phase of the KOHBRA study was planned and fulfilled successfully. The primary aim of phase I was to estimate the prevalence of $B R C A 1 / 2$ mutations and OC among a high-risk group of patients with $\mathrm{HBC}$ and their families. According to data collected during phase I of the study, the prevalence and penetrance of $B R C A$ mutations were comparable to corresponding data from Western countries. For the second phase of the KOHBRA study, we are currently investigating a Korean $B R C A$ mutation prediction model, prognostic factors in $B R C A$-related $\mathrm{BC}$, environmental/ genetic modifiers, and implementing a genetic counseling network. The final goal of the KOHBRA study is to create clinical practice guidelines for HBC in Korea. In this article, I review the genetics of HBC, summarize the characteristics of Korean $\mathrm{HBC}$, and discuss current and future $\mathrm{HBC}$ research in Korea.
\end{abstract}

Key Words: Hereditary breast cancer, BRCA mutation, KOHBRA study

\section{Introduction}

Breast cancer (BC) is the second most common cancer in Korean women. The age-adjusted annual incidence rate of $\mathrm{BC}$ in Korea is 43.8 per 100,000 women, and an estimated 13,400 new BC cases were expected to occur among Korean women in 2009." Incidence rates for female $\mathrm{BC}$ have increased annually over the past decade, and the current incidence rate is almost double that in 1999 (24.5/100,000). Although the exact causes of this increase are notknown, changes in dietary habits, reproductive factors, as well as increased screening and awareness of $\mathrm{BC}$ are all likely to have contributed to the observed rate.

While the incidence rate of $\mathrm{BC}$ is on the rise in Korea, it is still lower than that in Western countries (US: 76.0/100,000 for 2008). However, in contrast to Korea, the incidence rate for female BC has declined in theUSsince 2000. The dramatic decrease of almost 7\% from 2002 to 2003 has been attributed to reductions in the use of menopausal hormone therapy.

$\mathrm{BC}$ is a multifactorial disease, and the cause of $\mathrm{BC}$ is still not well defined. Both genetic and environmental factors have been linked to $B C$, and include hormone therapy, ionizing radiation, lifestyle, diet, and aging. Familial clustering of $\mathrm{BC}$ is common, and genetic

Received: 25 April 2012, Revised: 17 May 2012, Accepted: 22 May 2012, Published: 30 June 2012

*Corresponding author: Sung-Won Kim, MD, PhD, FACS

Department of Surgery, Breast Care Center, Seoul National University College of Medicine, Seoul National University Bundang Hospital, 300 Gumidong, Bundang-gu, Seongnam-si, Gyeonggi-do 463-707, Korea

Tel: +82-31-787-7094, Fax: +82-31-787-4055, E-mail: brcakorea@gmail.com

(c) This is an open-access article distributed under the terms of the Creative Commons Attribution Non-Commercial License (http://creativecommons.org/licenses/by-nc/3.0/) which permits unrestricted non-commercial use, distribution, and reproduction in any medium, provided the original work is properly cited.

(c) Copyright 2012 by the Korean Society of Medical Genetics 
predisposition accounts for 5\% to $10 \%$ of all BC cases. ${ }^{2)}$ Most hereditary breast cancer ( $\mathrm{HBC}$ ) cases are autosomal dominant, and disease characteristics include the early onset of disease ( $<45$ years of age), cancer of both breasts, and a high risk for the development of multiple cancers. Familial BC is defined as the occurrence of 2 or more $\mathrm{BC}$ cases within first and second degree relatives when there is no evidence of $\mathrm{HBC}$, whereas $\mathrm{BC}$ cases are characterized as sporadic when no BC has been reported within 2 generations. Many potential factors have been put forth to explain familial clustering and include exposure to common carcinogen/ s between family members living in close proximity; shared common risk factors associated with cultural or social behaviors (e.g., age at first full-term pregnancy); and the overlap of cancer-related dietary factors between family members due to socio-economic status.

The Korean Hereditary Breast Cancer (KOHBRA) study is a large, prospective, nationwide study. ${ }^{3)}$ Thirty-nine centers are registered in the Korean Breast Cancer Study Group and are participating in the KOHBRA study. Between May 2007 and May 2010, the first phase of the KOHBRAstudy was fulfilled successfully. The primary aims of the KOHBRA study leading up to 2010 were to estimate the prevalence of BRCA1/2 mutations and ovarian cancer (OC) among a high-risk group of patients with $\mathrm{HBC}$ and their families. The second aim of the KOHBRA study was to identify a Korean founder mutation related to familial breast or ovarian cancer, in order to determine non-familial predictors of $B R C A 1 / 2$ mutations and to establish a BRCA1/2 mutation carrier cohort. At the time of the last update of patient enrollment (February 2012), more than 2500 patients were enrolled, and more than 600 mutation carriers had been identified in the KOHBRA study. In this article, I review the genetics of $\mathrm{HBC}$ and summarize and discuss these findings in the context of $\mathrm{HBC}$ research in Korea.

\section{Genetics in hereditary breast cancer}

Recent studies have shown that HBC occurs in an autosomal dominant fashion, and to date, 5 or more high-penetrance genes, 4 intermediate-penetrance genes, and several low-penetrance genes have been identified. ${ }^{4,5)}$ The most common type of $\mathrm{HBC}$ is the site-specific breast cancer syndrome, in which familial clustering of breast cancer is observed in the absence of other types of cancer. $B R C A 1 / 2$ are the most important genes in this syndrome. Familial clustering of $\mathrm{BC}$ and $\mathrm{OC}$ are commonly observed in hereditary breast ovarian cancer syndrome, for which BRCA1/2 have also been identified as primary causative genes. Other rarer but highly penetrant genes such as TP53, PTEN, LKB1, and MSH2/MLH1 have also been identified in relation to $B C$ risk; syndromes related to mutations in these genes and BRCA1/2 are summarized in Table 1. There are also intermediate penetrance genes such as $A T M$, $C H E K 2$, PALB2, and BRIP1, and these genes are associated with a 2- to 3-fold increased lifetime risk of $\left.B C{ }^{6}{ }^{6}\right)$ Lastly, after the introduction of genome-wide association studies (GWAS), many lowpenetrance genes (1.25- to 1.65-fold increased lifetime risk of $\mathrm{BC}$ ) have been identified, and understanding their role in the development of $\mathrm{BC}$ is currently an active area of cancer research.

\section{BRCA1/BRCA2 and hereditary breast and ovarian cancer syndromes}

\section{1) BRCAgenes: Structure, function, and mutations}

In 1990, the early-onset breast cancer susceptibility gene was found to be located at 17q21 and was later cloned and identified as BRCA1. ${ }^{7)}$ Shortly after, in 1991, the same genetic marker, D17S74, was also found to be linked to $O C$ risk. ${ }^{8)}$ The entire sequence of BRCA1 was subsequently characterized in 1994. ${ }^{4)}$ The second breast cancer susceptibility gene was discovered by linkage analysis of 22 families with multiple early-onset BC and 1 or more male $\mathrm{BC}$ patients in a family. Due to a strong association between male BC and a polymorphic marker located at 13q1213 on chromosome 13, BRCA2 was identified, and in 1995, its full sequence was also characterized. ${ }^{5}{ }^{59}$

The BRCA1 gene is composed of 24 exons and encodes a protein of 1,863 amino acids. The large size of this gene makes functional analysis difficult. To date, more than 1,700 kinds of diseasecausing BRCA1 mutations have been reported, all of which are listed on the Breast Cancer Information Core website (BIC; http://research. nhgri.nih.gov/projects/bic/Member/index.shtml). Genomic rearrangements occur frequently in the BRCA1 gene, but these alterations are difficult to detect using standard polymerase chain reaction (PCR)-based techniques. Instead, the multiplex ligation-

Table 1. Hereditary breast cancer syndromes

\begin{tabular}{lcc}
\hline Syndromes & Genes & $\%$ in HBC \\
\hline Hereditary breast ovarian cancer syndrome & BRCA1/2 & $25-35 \%$ \\
Site-specific breast cancer syndrome & BRCA1/2 & $25-35 \%$ \\
& Unknown & $25-45 \%$ \\
Li-Fraumeni syndrome & TP53 & $<1 \%$ \\
Peutz-Jegher syndrome & LKB1 & $<1 \%$ \\
Cowden syndrome & PTEN & $<1 \%$ \\
Muir-Torre syndrome & MSH2, MLH1 & $<1 \%$ \\
\hline
\end{tabular}

HBC, Hereditary breast cancer 
dependent probe amplification (MLPA) method is primarily used to detect these mutations. Between 12\% and $36 \%$ of familial BC and $\mathrm{OC}$ patients are positive for large genomic rearrangements. ${ }^{10)}$

$B R C A 2$ is composed of 26 exons, and the coding region of this gene includes approximately $11.2 \mathrm{~Kb}$. This is almost twice the size of the $B R C A 1$ gene and is one of the largest genes identified. Like the $B R C A 1$ gene, due to its large size, the functional study of $B R C A 2$ is difficult to perform. However, in contrast to $B R C A 1$, large genomic rearrangements are not commonly observed in BRCA2 due to the absence of repeated sequences within the gene region. More than 1,800 disease-causing mutations have been identified and are reported in the BIC database. Interestingly, many characteristics are common between the mutations identified in both genes: mutations are found across each gene and do not occur in mutation "hot spots"; the majority of disease-causing mutations result in protein truncation; and none of the mutations identified in either gene are observed frequently in sporadic BC patients. ${ }^{11)}$

The proteins encoded by the 2 major breast cancer susceptibility genes, BRCA1 and BRCA2, are both involved in DNA repair and serve as protectors of the genome. ${ }^{12)}$ However, the 2 proteins work at different stages in the DNA damage response (DDR) and in DNA repair. $B R C A 1$ is a pleiotropic DDR protein that functions in both checkpoint activation and DNA repair, whereas BRCA2 is a mediator of the core mechanism of homologous recombination. The links between the 2 proteins are not well understood but must exist given the marked similarity in human cancer susceptibility associated with germline mutations in these genes. Both proteins work in concert to protect the genome from double-strand DNA damage during DNA replication.

\section{2) Founder mutation}

The roles of $B R C A$ mutations in the occurrence of $\mathrm{BC}$ in general populations were clarified through the study of a small number of founder mutations. A founder mutation is a mutation that appears in the DNA of 1 or more individuals who are founders of a distinct population. Founder mutations result from changes that occur in the DNA sequence and get passed down to subsequent generations. For example, 3 founder mutations that are frequently seen in Ashkenazi Jewish populations are BRCA1 185delG and 5382insC and BRCA2 6174delT.13) The frequency of these 3 founder mutations in Ashkenazi women are about 2.5\% but 12\% in the general population of Ashkenazi BC patients and $30 \%$ in Ashkenazi early-onset $\mathrm{BC}$ patients. Although other BRCA mutations are also seen in the Ashkenazi Jewish population, these 3 founder mutations account for $90 \%$ of all mutations found in this population. ${ }^{14-16)}$ The most common BRCA2 founder mutation, BRCA2 999del5, was identified in the Icelandic population; in Icelanders, this mutation occurs at a frequency of $0.5 \%$ in women, but its frequency is at $8 \%$ in the general population of BC cases and $24 \%$ in early-onset BC patients. ${ }^{17)}$ In addition to these populations, common founder mutations have also been reported in other countries, including Finland, Hungary, Russia, France, the Netherlands, and Norway.

Mutations reported in the KOHBRA study are listed in Table 2 in the order of frequency. Unlike in Western countries, BRCA2 mutations are seen more frequently in the Korean population, $B R C A 2$ $7708 \mathrm{C}>\mathrm{T}$ (c. $7480 \mathrm{C}>\mathrm{T})$ being the most frequent. This mutation has been reported many times, and was identified as a founder mutation by Seong etal. on the basis of haplotype analysis. ${ }^{18)}$

\section{3) Prevalence of $B R C A$ mutations}

Most of the prevalence studies have been conducted in families with a high incidence of $\mathrm{BC}$ and/or $\mathrm{OC}$. Linkage analysis of $\mathrm{HBC}$ families participating in the Breast Cancer Linkage Consortium

Table 2. The candidates for the Korean founder mutation ${ }^{3)}$

\begin{tabular}{lllllc} 
& Systematic nomenclature & BIC nomenclature & Effect on amino acid & $\mathrm{N}^{*}$ & $\%$ \\
\hline BRCA2 & c.7480C>T & 7708C>T & p.Arg2494X & 18 & 12.2 \\
BRCA1 & c.390C>A & 509C>A & p.Tyr130X & 11 & 7.4 \\
BRCA1 & C.5496_5506del11insA & 5615_5625del11insA & p.Val1833SerfsX7 & 11 & 7.4 \\
BRCA2 & C.1399A>T & 1627A>T & p.Lys467X & 8 & 5.4 \\
BRCA2 & c.3744_3747delTGAG & 3972_3975delTGAG & p.Ser1248ArgfsX10 & 7 & 4.7 \\
BRCA2 & c.6724_6725delGA & 6952_6953delGA & p.Asp2242PhefsX2 & 5 & 3.4 \\
BRCA1 & c.3627_3628insA & 3746_3747insA & p.Glu1210ArgfsX9 & 4 & 2.7 \\
BRCA1 & c.5445G>A & 5564G>A & p.Trp1815X & 4 & 2.7 \\
BRCA2 & C.5576_5579delTTAA & 5804_5807delTTAA & p.lle1859LysfsX3 & 4 & 2.7 \\
BRCA1 & c.992_994delAGCinsT & 1041_1043delAGCinsT & p.Ser308X & 3 & 2 \\
\hline
\end{tabular}

${ }^{*}$ Number of times mutation observed (total=148).

BIC, Breast Cancer Information Core. 
(all of which had at least 4 cases of breast cancer either in women under the age of 60 years, with or without $0 C_{\text {, }}$ or in men) indicated that $87 \%$ of such families could be genetically linked to mutations in either BRCA1 or BRCA2.19) For unselected families that had a low incidence of $B C$ or $O C$, the prevalence of $B R C A$ mutations was $55 \%$ for BC and OC families and 75\% for families with cases in which both $\mathrm{BC}$ and $\mathrm{OC}$ were observed in a single patient. ${ }^{20,21)}$ Taken together, the prevalence of $B R C A$ mutations in early-onset $\mathrm{BC}$ (diagnosis $<45$ year of age) is 10-18\% (6-13\% for BRCA1 and $4-5 \%$ for $B R C A 2)_{1}{ }^{2022-24)}$ whereas the prevalence of $B R C A$ mutations in the general population of $B C$ patients is estimated to be less than $3 \%{ }^{25,26)}$

The BRCA1 W1815X mutation was first reported in Korea by Oh et al. in $1995 .{ }^{27)}$ Studies on early-onset BC patients in Korea revealed that $15 \%$ of patients were mutation carriers. ${ }^{28)}$ However, only $3 \%$ of sporadic $\mathrm{BC}$ patients have been identified with $B R C A$ mutations. ${ }^{29)}$ According to an interim analysis of data collected by the KOHBRA study, $24.8 \%$ of BC patients with a family history of $\mathrm{BC}$ or $\mathrm{OC}, 11.3 \%$ of early-onset (age, $<35$ years) $\mathrm{BC}, 22.1 \%$ of bilateral $\mathrm{BC}, 8.3 \%$ of male $\mathrm{BC}$, and $33.4 \%$ of patients with both $\mathrm{BC}$ and $\mathrm{OC}$ were carriers of $B R C A$ mutations. ${ }^{30)}$

Genomic rearrangement occasionally affects the $B R C A 1 / 2$ genes in Caucasian breast cancer patients. Seong et al. investigated the contribution of BRCA1/2 genomic rearrangements in high-risk breast cancer patients in the Korean population. ${ }^{18)}$ They screened for BRCA1/2 genomic rearrangements using MLPA in 122 high-risk breast cancer patients who tested negative for BRCA1/2 mutations. A novel deletion of exons 13-15 in BRCA1 was identified in 1 patient (frequency $=0.8 \%$ ). They concluded that subsequent screening for $B R C A 1 / 2$ genomic rearrangements should be considered in highrisk Korean breast cancer patients who test negative for BRCA1/2 mutations. However, BRCA1/2 genomic rearrangements are likely to make only a small contribution to breast cancer in high-risk Korean population. ${ }^{311}$

\section{4) Penetrance of $B R C A$ mutations}

Germline mutations in BRCA1 and BRCA2 confer high risks of $\mathrm{BC}$ and $\mathrm{OC}$, and according to modified segregation analysis, the average cumulative risks for $B R C A 1$ mutation carriers by the age of 70 years was estimated to be $65 \%$ (95\% confidence interval 44-78\%) for breast cancer and 39\% (18-54\%) for OC; and the corresponding estimates for BRCA2 were 45\% (31-56\%) and $11 \%(2.4-19 \%) .{ }^{32)}$

In Korea, to estimate the cumulative risk of $\mathrm{BC}$ and $\mathrm{OC}$ for each age group among female family members of patients with $B R C A 1$ and BRCA2 mutations, Kaplan-Meier analyses were performed for 61 BRCA1 mutation carriers in 42 families and 47 BRCA2 mutation carriers in 31 families. By the age of 70 years, female breast cancer risk for the BRCA1 and BRCA2 mutation carriers was estimated to be $72.1 \%$ (59.5-84.8\%) and 66.3\% (41.2-91.5\%), respectively, and OC risk, 24.6\% (0-50.3\%) and 11.1\% (0-31.6\%), respectively. The contralateral breast cancer risk at 5 years after primary breast cancer was estimated to be 16.2\% (9.3-23.1\%) for BRCA1 mutation carriers and 17.3\% (9.7-24.0\%) for BRCA2 mutation carriers. According to these findings, the penetrance of $B R C A$ mutations in Korea is largely consistent with previous studies in Western populations. However, the small number of cases, the high proportions of probands in the study subjects, access to only short term follow-up data, and large confidence intervals limit the conclusions that can be made from thisstudy. ${ }^{33}$

The actual penetrance of $B R C A$ mutations varies according to modifiers. Tamoxifen might be one of the most potent modifiers of $B R C A$ penetrance. For example, 5 -years of tamoxifen therapy lowers the chance of $\mathrm{BC}$ development by $50 \%$. Risk-reducing salpingo-oophorectomy also reduces BC risk by $50 \%$ and OC risk by $95 \% .{ }^{34)}$ Several studies have investigated the roles of genetic modifiers of $B R C A$ genes. The Consortium of Investigators of Modifiers of BRCA1 and BRCA2 (CIMBA) is a multinational consortium focused on characterizing genetic modifiers of $B R C A$ genes. To date, candidate gene studies and GWAS have revealed several genetic modifiers of BRCA1/2 genes, such as RAD51, FGFR2, CASP8, TOX3/TNRC9, MAP3K1, LSP1, 2q35, and C19orf62/ ANKLE1. ${ }^{35)}$

\section{Clinical characteristics and management of HBC}

\section{1) Clinical characteristics of HBC}

The clinical and pathologic features of $B R C A$-related $B C$ are summarized in Table 3. The characteristic features of BRCA1-related $B C$ include a high histologic grade, a high proliferation index, and increased occurrence of atypical medullary cancer. Mean age at diagnosis of BRCA1-related $\mathrm{BC}$ is 10 years earlier than that for BRCA2related and sporadic $B C$. The primary characteristic of $B R C A 1-$ related $B C$ is ER negativity; $70 \%$ of $B R C A 1$-related $B C$ cases are negative for estrogen receptor (ER) and progesterone receptor (PR). Also, Her2 overexpression is rare, and thus, triple negative $\mathrm{BC}$ is common for BRCA1 carriers. BRCA1-related $\mathrm{BC}$ showed a basal-like phenotype in mRNA expression profile, with higher expression of $p 53, c y c l i n E_{1}$ and $M Y C_{1}$ and lower expression of $K I P 1{ }^{36)}$ Angiogenesis is also more common for BRCA1 carriers. Ductal carcinoma in situ is rare in $B R C A 1$ carriers. In contrast, ductal carcinoma is common in BRCA2-related $\mathrm{BC}$, as is ER expression 
(70\%). The mean age at diagnosis of BRCA2-related $B C$ is the same as that for sporadic BC.

There are conflicting data for the prognosis of $B R C A$-related $B C{ }^{37)}$ Some of the discrepancies may be explained by methodological differences or biases. Triple negative type $\mathrm{BC}$ is common in BRCA1related $\mathrm{BC}$, and it has been suggested that $B R C A 1$-related $\mathrm{BC}$ cases tend to have worse prognoses; to date, no studies have shown a survival advantage for BRCA1 mutation carriers. The prognosis for $B R C A 2$-related BC casesismoresimilar to that of sporadic cases. ${ }^{38)}$

\section{2) Management of unaffected $B R C A$ mutation carriers}

The primary goals for the management of unaffected $B R C A$ mutation carriers are prevention and early detection of cancer development. To this end, 3 strategies have been implemented: surveillance, chemoprevention, and risk-reducing surgery. According to National Comprehensive Cancer Network (NCCN) Guidelines 2011, training in breast self-examination with regular monthly practice should begin at 18 years of age, and semiannual clinical breast examinations should begin by age 25 for women who are carriers of BRCA1/2 mutations. In addition, these women should begin having annual mammograms and breast MRI screening at age 25 or on an individualized timetable based on the earliest age of cancer onset in family members. For the purpose of early detection of $\mathrm{OC}$, women not opting for $\mathrm{OC}$ risk-reducing surgery should consider concurrent transvaginal ultrasonography and CA125 determination every 6 months, starting at age 35, or 5-10 years before the earliest age of first diagnosis of $\mathrm{OC}$ in the family.

Carriers of BRCA mutationsshould also consider chemoprevention options for $\mathrm{BC}$ and $\mathrm{OC}$, including discussing risks and benefits. Half of $B C$ cases can be prevented by 5 years of tamoxifen use in $B R C A 2$ mutation carriers. However, tamoxifen use has not been associated with a reduction in $\mathrm{BC}$ risk in those with $B R C A 1$ muta- tions ${ }^{39)}$ although it is important to note that this analysis was conducted on a very small number of individuals with BRCA1/2 mutations. Oral contraceptive use significantly reduced the risk of OC by approximately $50 \%$ for both BRCA1 and BRCA2 mutation carriers. ${ }^{40)}$ However, studies on the effects of oral contraceptive use on $\mathrm{BC}$ risk among $B R C A$ mutation carriers have reported conflicting data. ${ }^{41,42)}$

The NCCN Guidelines also support discussion of the option of risk-reducing mastectomy (RRM) for women on a case-by-case basis. Counseling regarding the degree of protection offered by such surgery and the degree of cancer risk should be provided. The panel recommends bilateral risk-reduction salpingo-oophorectomy (RRSO) for women with a known BRCA mutation, ideally between the ages 35 and 40 years, upon completion of child bearing, or at an individualized age based on the earliest age of OC diagnosed in the family. Ninety percent of BC can be prevented by RRM, and 97\% of OC can be prevented by RRSO ${ }^{43}$ RRSO is also reported to reduce the risk of $\mathrm{BC}$ in carriers of $B R C A$ mutations by approximately $50 \%{ }^{44)}$ According to a prospective, multicenter cohort study,

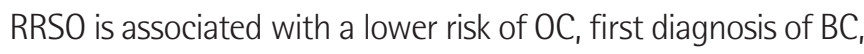
all-cause mortality, BC-specific mortality, and OC-specific mortality. ${ }^{45)}$ RRS is not commonly performed in Korea; ${ }^{46)}$ the first reports of contralateral RRM and bilateral RRM were in 2008 and 2010, respectively. ${ }^{47,48)}$

\section{Rare gene mutations and syndromes}

\section{1) TP53 and Li-Fraumeni syndrome}

Germline mutations in the TP53 gene cause Li-Fraumeni syndrome (LFS), which is inherited in an autosomal dominant fashion. LFS was first reported in 1969 by Li and Fraumeni and is often referred to as SBLA syndrome, named after the first letter

Table 3. Genetic modifiers of cancer risk for BRCA1 and BRCA2 mutation carriers

\begin{tabular}{|c|c|c|c|c|c|}
\hline \multirow{2}{*}{ Genes/Loci } & \multirow{2}{*}{ SNP } & \multicolumn{2}{|c|}{ BRCA1 } & \multicolumn{2}{|c|}{ BRCA2 } \\
\hline & & $\mathrm{RR}$ & $95 \% \mathrm{Cl}$ & $\mathrm{RR}$ & $95 \% \mathrm{Cl}$ \\
\hline RAD51 & rs1801320 & 1.59 & $0.96-2.63$ & 3.18 & $1.39-7.27$ \\
\hline CAPS & $\mathrm{D} 302 \mathrm{H}$ & 0.85 & $0.76-0.97$ & 1.06 & $0.88-1.27$ \\
\hline FGFR2 & rs2981522 & 1.02 & $0.95-1.09$ & 1.32 & $1.20-1.45$ \\
\hline TOX3/TNRC9 & rs3803662 & 1.11 & $1.03-1.19$ & 1.15 & $1.03-1.27$ \\
\hline MAP3K1 & rs889312 & 0.99 & $0.93-1.06$ & 1.12 & $1.02-1.24$ \\
\hline$\angle S P 1$ & rs3817198 & 1.05 & $0.99-1.11$ & 1.16 & $1.07-1.25$ \\
\hline $2 q 35$ & rs13387042 & 1.14 & $1.04-1.25$ & 1.18 & $1.04-1.33$ \\
\hline $8 q 24$ & rs13281615 & 1.00 & $0.94-1.05$ & 1.06 & $0.98-1.14$ \\
\hline C19orf62/ANKLE1 & rs8170 & 1.26 & $1.17-1.35$ & 0.90 & $0.77-1.05$ \\
\hline C19orf62/ANKLE1 & rs2363956 & 0.84 & $0.80-0.89$ & 1.12 & $0.99-1.27$ \\
\hline
\end{tabular}

Table adapted from reference 34 . $\mathrm{Cl}$, confidential interval; RR, relative risk 
of the cancers that occur frequently in LFS: soft tissue sarcoma, osteosarcoma, brain tumor, BC, leukemia, lymphoma, and adrenocortical carcinoma. ${ }^{49)}$ Fifty percent of LFS cases are due to mutations in the TP53 gene, and unlike BRCA gene mutations, missense mutations are most common. Lifetime cancer risk for TP53 mutation carriers is 73\% in men and 100\% in women. The cumulative risk of $\mathrm{BC}$ in women over the age of 40 with TP53 mutations is greater than $60 \% .{ }^{50)}$ The first report of LFS in Korea was in 1995 by Bang et al., and the first report of an LFS case with a TP53 missense mutation was in $2008^{511}$

\section{2) PTEN and Cowden syndrome}

Lloyd and Dennis were the first to report a case of Cowden syndrome in 1963; they also identified a mutation in the PTEN gene as the causative factor. ${ }^{52)}$ This syndrome is characterized by breast, endometrial, thyroid, kidney, and colorectal cancers; dermatologic features, such as oral and skin papillomas, trichilemmomas; gastrointestinal features, such as mixed polyposis, including hamartomas; and neurologic features, such as autism and Lhermitte-Duclos disease. Lifetime risk of BC in patients with Cowden syndrome is 25-50\%. There have been 3 reports of Cowden syndrome with $\mathrm{BC}$ in Korea. ${ }^{53-55)}$ However, PTEN mutations were not involved in any of these 3 cases. ${ }^{56,57)}$

\section{3) $L K B 1$ and Peutz-Jegher syndrome}

Peutz-Jeghers syndrome, also known as hereditary intestinal polyposis syndrome, is an autosomal dominant genetic disease characterized by the development of benign hamartomatous polyps in the gastrointestinal tract and hyperpigmented macules on the lips and oral mucosa. These patients have elevated risks of breast, uterine cervix, ovarian, testicular, and pancreatic cancer. The risk of $\mathrm{BC}$ is up to 20 -fold higher than the risk of the general population, and the STK11/LKB1 gene is known as the primary cause of the syndrome. ${ }^{58)}$ To date, two cases of Peutz-Jeghers syndrome with BC have been reported. ${ }^{59)}$

\section{4) $M S H 2, M L H 1$, and Muir-Torre syndrome}

Muir-Torre syndrome (MTS) is an inherited cancer syndrome that is thought to be a subtype of hereditary nonpolyposis colorectal cancer. Individuals with MTS are prone to develop cancers of the colon, breasts, and genitourinary tract, as well as skin lesions, such as keratoacanthomas and sebaceous tumors. Causative mutations have been identified in $M L H 1$ and $M S H 2$, which are involved in DNA mismatch repair. BC develops in 25\% of MTS patients. ${ }^{60)}$ The first report of the MTS syndrome with BC was reported in $2010 .{ }^{611}$

\section{5) Othergenes}

The CHEK2 gene is located on chromosome 22 and encodes a protein kinase involved in the cell cycle that is activated in response to DNA damage. Patients with the CHEK2 110delC mutation have twice the elevated risk of $\mathrm{BC}$ in the European population. The CHEK2 mutation has been detected in 13.5\% of BRCA-negative $B C$ patients with at least 1 family member with $B C$. This mutation also results in a 10-fold increase of $\mathrm{BC}$ risk in men. ${ }^{43)}$ However, the CHEK2 mutation appears to be rare in the Korean population. ${ }^{62)}$

The PALB2 gene encodes a protein that functions in genome maintenance (double strand break repair). The PALB2 protein binds to and colocalizes with BRCA2 in nuclear foci and likely permits the stable intranuclear localization and accumulation of $B R C A 2$. The PALB2 gene is also known as the Fanconi anemia gene, FANCN; a biallelic mutation of this gene results in $\mathrm{N}$ type Fanconi anemia. The monoallelic $P A L B 2$ gene mutation results in elevated risk of $\mathrm{BC}$ (2- to 3-fold) and pancreatic cancer. ${ }^{63)}$ The prevalence of this gene mutation is about 0.6-3\% in familial BC patients, ${ }^{64,65)}$ although it is rare in the Korean population. ${ }^{66)}$

$B R I P 1$ is a helicase and works with the $B R C A 1$ protein to repair

Table 4. Clinical features of hereditary breast cancer

\begin{tabular}{|c|c|c|}
\hline & BRCA1 carriers & BRCA2 carriers \\
\hline Age of onset of breast cancer & $80 \%$ at $<50$ years of age & Same as sporadic cases \\
\hline \multirow[t]{3}{*}{ Pathologic features } & Invasive ductal cancer (75\%) & Invasive ductal cancer (75\%) \\
\hline & Atypical medullary cancer ( 10\%) & Atypical medullary cancer $(<5 \%)$ \\
\hline & & Invasive lobular cancer ( 10\%) \\
\hline Histologic grade & Poorly differentiated (75\%) & Moderately differentiated (45\%) or poorly differentiated (45\%) \\
\hline Estrogen receptor & Negative (75\%) & Positive (75\%) \\
\hline Her2 & Negative (95\%) & Negative (95\%) \\
\hline p53 & Positive (50\%) & Positive (40\%) \\
\hline Cyclin D1 & Negative (90\%) & Positive (60\%) \\
\hline Ductal carcinoma in situ & Rare & Common \\
\hline
\end{tabular}


of DNA. This gene is also called FANCJ because biallelic BRIP1 mutations result in J type Fanconi anemia. Monoallelic mutations in $B R I P 1$ elevate BC risk 2-fold. ${ }^{67)}$

\section{6) Low-penetrance genes}

Common low-penetrance alleles are important to public health because a large proportion of the population carries such alleles, and together with multiple environmental factors, such mutations make an important contribution to disease susceptibility. Recently, an association study revealed many candidate genes, which can be categorized in the following way; genes related to steroid hormone metabolism (COMT, CYP17, CYP19, CYP2D6, ER, PR, $E D H 17 \beta 2$, etc.); genes related to carcinogen metabolism (CYP1A1, CYP2E1, CYP1B1, GSTM1, GSTT1, GSTP1, NAT1, NAT2, NOO1, etc.); DNA repair genes $(X R C C 1, X R C C 3, E R C C 1, A T M, M G M T, X P D, X P F$, $O G G 1$, etc.); epigenetic genes related to tumor growth (TNF- $\alpha$, $T N F-\beta, I G F, I L-1 \beta, I L-6, I L-10$, etc.); and other gene groups (cyclin D1, $M n S O D, M T H F R, V D R$, etc.). In addition, a recent meta-analysis of 279 genes further defined associations between many of these genes with $\mathrm{BC}$. They found that 10 variants in 6 genes (ATM, CASP8, CHEK2, CTLA4, NBN) exhibited strong association to BC, 4 variants in 4 genes (ATM, CYP19A1, TERT, XRCC3) had a moderate level of association, and 37 variants had a weak association with BCrisk. ${ }^{68)}$

\section{7) Genetic counseling in Korea}

Genetic counseling is an essential part of genetic testing and should be performed by the specialist. Before the initiation of the KOHBRA Study in 2007, we performed a nationwide survey that included questionnaire data from 43 doctors from 42 institutions. According to the survey, $81.4 \%$ of the respondents answered that they collected information about family history of $\mathrm{BC}$ and $\mathrm{OC}$, and $58.2 \%$ recommended genetic testing to patients with proper indication. However, only half of the respondents answered that they offered genetic counseling alongside genetic testing. When genetic counseling was conducted, it was carried out by the breast surgeons themselves $(81 \%)$ or by nurses $(19 \%){ }^{69)}$

We conducted a follow-up survey 2 years after the initiation of the KOHBRAstudy. According to the 2009 follow-up survey, most physicians (60.0\%) tended to draw a pedigree, which was higher than that reported in the initial 2007 survey (48.0\%). The rate of genetic test recommendations for patients at risk for $\mathrm{HBC}$ was higher in the 2009 survey (84.0\%) compared to the 2007 survey (64.0\%). Fifteen of 25 participants (60.0\%) provided genetic counseling before their patients underwent a genetic test, which was higher than that (40.0\%) in the 2007 survey. We believe that the
KOHBRA study has played an important role in the appropriate selection of candidates for genetic testing. ${ }^{70)}$

In 2011, to enhance the quality of genetic counseling and to increase the rate of genetic counseling, the Korean Breast Cancer Society set up genetic counseling as part of a HBOC training program and certified 13 genetic counselors for HBC in 2012; this program currently operates annually, and there are no plans for its discontinuation.

\section{8) Future research}

The KOHBRA Study is planned as a 10-year project to develop clinical practice guidelines (CPG) for HBC in Korea. In the first phase of the KOHBRA study, we investigated the prevalence of $B R C A$ mutations in the Korean population. Currently, we are in the second phase, the aims of which are as follows: (1) to develop a Korean BRCA mutation prediction model; (2) to discover the characteristics and prognostic factors contributing to $B R C A$ related $B C ;$ (3) to study the environmental/genetic modifiers of $B R C A$ gene mutations; and (4) to build and implement an HBC genetic counseling network in Korea. The Korean Breast Cancer Society has been publishing the CPG for BC every otheryear and is currently under revising process for the fifth edition in 2013. CPG for $\mathrm{HBC}$ will be incorporated into the fifth edition of $\mathrm{BC}$ management CPG. More detailed information about the KOHBRAstudy is available on the KOHBRA homepage (www.kohbra.kr).

The KOHBRA Study is actively participating in an international collaborative study of $\mathrm{BC}$. We are collaborating with the International BRCA Carrier Cohort Study (IBCCS) and CIMBA. The IBCCS is focusing on epidemiological risk factors, and CIMBA is focusing on the involvement of genetic modifiers of BRCA mutations in $B C$ risk. In addition to this collaboration, KOHBRA recently started the Asian BRCA Consortium (ABRCA) which involves collaborations among 7 countries: Korea, Japan, China, Indonesia, Hong Kong, Malaysia, and Singapore. The primary aims of ABRCA are as follows. First, to share the knowledge of HBOC between Asian countries; second, to improve the quality of care for HBOC patients in Asia; and third, to undertake collaborative research on HBOC in Asia. $A B R C A$ will also hold annual meetings to promote each of these initiatives.

\section{Acknowledgment}

This study was partly supported by a grant from the National R\&tD Program for Cancer Control, Ministry for Health, Welfare, and FamilyAffairs, Republic of Korea (\#1020350). 


\section{References}

1. National Cancer Center. National Cancer Registry Statistics 2009.

2. Claus EB, Schildkraut JM, Thompson WD, Risch NJ. The genetic attributable risk of breast and ovarian cancer. Cancer 1996;77:2318-24.

3. Han SA, Park SK, Ahn SH, Lee MH, Noh DY, Kim LS, et al. The Korean Hereditary Breast Cancer (KOHBRA) study: protocols and interim report. Clin Oncol (R Coll Radiol) 2011;23:434-41.

4. Miki Y, Swensen J, Shattuck-Eidens D, Futreal PA, Harshman K, Tavtigian $\mathrm{S}$, et al. A strong candidate for the breast and ovarian cancer susceptibility gene BRCA1. Science 1994;266:66-71.

5. Wooster R, Bignell G, Lancaster J, Swift S, Seal S, Mangion J, et al. Identification of the breast cancer susceptibility gene BRCA2. Nature 1995:378:789-92.

6. Stratton MR, Rahman N. The emerging landscape of breast cancer susceptibility. Nat Genet 2008;40:17-22.

7. Hall JM, Lee MK, Newman B, Morrow JE, Anderson LA, Huey B, et al. Linkage of early-onset familial breast cancer to chromosome 17q21. Science 1990;250:1684-9.

8. Narod SA, Feunteun J, Lynch HT, Watson P, Conway T, Lynch J, et al. Familial breast-ovarian cancer locus on chromosome 17q12-q23. Lancet 1991;338:82-3.

9. Tavtigian SV, Simard J, Rommens J, Couch F, Shattuck-Eidens D, Neuhausen $\mathrm{S}$, et al. The complete BRCA2 gene and mutations in chromosome 13q-linked kindreds. Nat Genet 1996;12:333-7.

10. Woodward $A M$, Davis $T A$, Silva $A G$, Kirk JA, Leary JA. Large genomic rearrangements of both $B R C A 2$ and $B R C A 1$ are a feature of the inherited breast/ovarian cancer phenotype in selected families. J Med Genet 2005; 42:e31.

11. Teng DH, Bogden R, Mitchell J, Baumgard M, Bell R, Berry S, et al. Low incidence of BRCA2 mutations in breast carcinoma and other cancers. Nat Genet 1996;13:241-4.

12. Roy R, Chun J, Powell SN. BRCA1 and BRCA2: different roles in a common pathway of genome protection. Nat Rev Cancer 2012;12:68-78.

13. Struewing JP, Abeliovich $D$, Peretz $T$, Avishai $N$, Kaback MM, Collins FS, et al. The carrier frequency of the BRCA1 185delAG mutation is approximately 1 percent in Ashkenazi Jewish individuals. Nat Genet 1995;11:198-200.

14. Frank TS, Deffenbaugh AM, Reid JE, Hulick M, Ward BE, Lingenfelter $B$, et al. Clinical characteristics of individuals with germline mutations in BRCA1 and BRCA2: analysis of 10,000 individuals. J Clin Oncol 2002; 20:1480-90.

15. Kauff ND, Perez-Segura P, Robson ME, Scheuer $L$, Siegel $B$, Schluger $A$, et al. Incidence of non-founder BRCA1 and BRCA2 mutations in high risk Ashkenazi breast and ovarian cancer families. J Med Genet 2002; 39:611-4.

16. Phelan CM, Kwan E, Jack E, Li S, Morgan $C$, Aube J, et al. A low frequency of non-founder BRCA1 mutations in Ashkenazi Jewish breast-ovarian cancer families. Hum Mutat 2002;20:352-7.

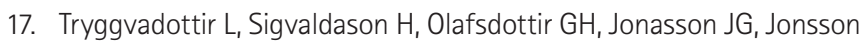

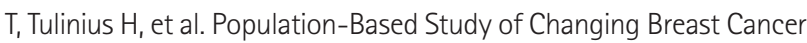
Risk in Icelandic BRCA2 Mutation Carriers, 1920-2000. J Natl Cancer Inst 2006;98:116-22.

18. Seong MW, Cho S, Noh DY, Han W, Kim SW, Park CM, et al. Comprehensive mutational analysis of BRCA1|BRCA2 for Korean breast cancer patients: evidence of a founder mutation. Clin Genet 2009;76:152-60.

19. Ford D, Easton DF, Stratton M, Narod S, Goldgar D, Devilee P, et al. Genetic heterogeneity and penetrance analysis of the BRCA1 and BRCA2 genes in breast cancer families. The Breast Cancer Linkage Consortium. Am J Hum Genet 1998;62:676-89.

20. Couch FJ, DeShano ML, Blackwood MA, Calzone K, Stopfer J, Campeau $\mathrm{L}$, et al. BRCA1 mutations in women attending clinics that evaluate the risk of breast cancer. N Engl J Med 1997;336:1409-15.

21. Shih HA, Couch FJ, Nathanson KL, Blackwood MA, Rebbeck TR, Armstrong $\mathrm{KA}$, et al. BRCA1 and BRCA2 mutation frequency in women evaluated in a breast cancer risk evaluation clinic. J Clin Oncol 2002; 20:994-9.

22. Langston AA, Malone $K E$, Thompson JD, Daling JR, Ostrander EA. BRCA1 mutations in a population-based sample of young women with breast cancer. N Engl J Med 1996;334:137-42.

23. Malone KE, Daling JR, Neal C, Suter NM, O'Brien C, Cushing-Haugen $\mathrm{K}$, et al. Frequency of BRCA1/BRCA2 mutations in a population-based sample of young breast carcinoma cases. Cancer 2000;88:1393-402.

24. Peto J, Collins N, Barfoot R, Seal S, Warren W, Rahman N, et al. Prevalence of BRCA1 and BRCA2 gene mutations in patients with early-onset breast cancer. J Natl Cancer Inst 1999;91:943-9.

25. Newman B, Mu H, Butler LM, Millikan RC, Moorman PG, King MC Frequency of breast cancer attributable to $B R C A 1$ in a population-based series of American women. JAMA 1998;279:915-21.

26. Kim SW, Lee CS, Fey JV, Borgen PI, Boyd J. Prevalence of BRCA2 mutations in a hospital based series of unselected breast cancer cases. J Med Genet 2005;42:e5.

27. Oh JH, Noh DY, Choe KJ, Kang SB, Kim LS, Ro MS, et al. Germline mutation of BRCA1 gene in Korean breast and ovarian cancer patients. J Korean Cancer 1995;27:1061-9.

28. Choi DH, Lee MH, Bale $A E$, Carter $D$, Haffty $B G$. Incidence of $B R C A 1$ and BRCA2 mutations in young Korean breast cancer patients. J Clin Oncol 2004;22:1638-45.

29. Han $S H$, Lee $K R$, Lee $D G$, Kim BY, Lee KE, Chung WS. Mutation analysis of BRCA1 and BRCA2 from 793 Korean patients with sporadic breast cancer. Clin Genet 2006;70:496-501.

30. Han SA, Park SK, Ahn SH, Lee MH, Noh DY, Kim LS, et al. The Korean Hereditary Breast Cancer (KOHBRA) Study: Protocols and Interim Report. Clin Oncol (R Coll Radiol) 2011;23:434-41.

31. Seong MW, Cho SI, Noh DY, Han W, Kim SW, Park CM, et al. Low contribution of BRCA1/2 genomic rearrangement to high-risk breast cancer in the Korean population. Fam Cancer 2009;8:505-8. 
32. Antoniou $A$, Pharoah $P D$, Narod $S$, et al. Average risks of breast and ovarian cancer associated with BRCA1 or BRCA2 mutations detected in case series unselected for family history: a combined analysis of 22 studies. Am J Hum Genet 2003;72:1117-30.

33. Han SA, Park SK, Ahn SH, Son BH, Lee MH, Choi DH, et al. The Breast and Ovarian Cancer Risks in Korea Due to Inherited Mutations in BRCA1 and BRCA2: A Preliminary Report. J Breast Cancer 2009;12:92-9.

34. Kauff ND, Satagopan JM, Robson ME, Scheuer L, Hensley M, Hudis CA, et al. Risk-reducing salpingo-oophorectomy in women with a BRCA1 or BRCA2 mutation. N Engl J Med 2002;346:1609-15.

35. Milne RL, Antoniou AC. Genetic modifiers of cancer risk for BRCA1 and BRCA2 mutation carriers. Ann Oncol 2011; 22 Suppl 1:i11-7.

36. Turner NC, Reis-Filho JS. Basal-like breast cancer and the BRCA1 phenotype. Oncogene 2006;25:5846-53.

37. Goodwin PJ, Phillips KA, West DW, Ennis M, Hopper JL, John EM, et al. Breast cancer prognosis in BRCA1 and BRCA2 mutation carriers: an International Prospective Breast Cancer Family Registry populationbased cohort study. J Clin Oncol 2012;30:19-26.

38. Bordeleau L, Panchal S, Goodwin P. Prognosis of BRCA-associated breast cancer: a summary of evidence. Breast Cancer Res Treat 2010;119:1324.

39. King MC, Wieand $S$, Hale $K$, Lee $M$, Walsh $T$, Owens $K$, et al. Tamoxifen and breast cancer incidence among women with inherited mutations in BRCA1 and BRCA2: National Surgical Adjuvant Breast and Bowel Project (NSABP-P1) Breast Cancer Prevention Trial. JAMA 2001;286: 2251-6.

40. Narod SA, Risch H, Moslehi R, Dorum A, Neuhausen S, Olsson H, et al. Oral contraceptives and the risk of hereditary ovarian cancer. Hereditary Ovarian Cancer Clinical Study Group. N Engl J Med 1998;339:424-8.

41. Narod SA, Dube MP, Klijn J, Lubinski J, Lynch HT, Ghadirian P, et al. Oral contraceptives and the risk of breast cancer in BRCA1 and BRCA2 mutation carriers. J Natl Cancer Inst 2002;94:1773-9.

42. Haile RW, Thomas DC, McGuire V, Felberg A, John EM, Milne RL, et al. BRCA1 and BRCA2 mutation carriers, oral contraceptive use, and breast cancer before age 50. Cancer Epidemiol Biomarkers Prev 2006; 15:1863-70.

43. Meijers-Heijboer $H_{\text {, van }}$ Geel $B$, van Putten $W L$, Henzen-Logmans $\mathrm{SC}$, Seynaeve C, Menke-Pluymers MB, et al. Breast cancer after prophylactic bilateral mastectomy in women with a BRCA1 or BRCA2 mutation. N Engl J Med 2001;345:159-64.

44. Rebbeck TR, Lynch HT, Neuhausen SL, Narod SA, Van't Veer L, Garber

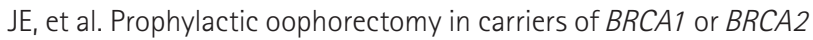
mutations. N Engl J Med 2002;346:1616-22.

45. Domchek SM, Friebel TM, Singer CF, Evans DG, Lynch HT, Isaacs $C$, et al. Association of risk-reducing surgery in BRCA1 or BRCA2 mutation carriers with cancer risk and mortality. JAMA 2010;304:967-75.

46. Koo DH, Chung IY, Kang E, Han SA, Kim SW. Usage Patterns of Surveillance, Chemoprevention and Risk-Reducing Surgery in Korean BRCA Mutation Carriers: 5 Years of Experience at a Single Institution. J Breast
Cancer 2011;14:S17-S23.

47. Kim KS, Kim S, Han SA, Kang E, Jeon YT, Ha TH, et al. Contralateral Prophylactic Mastectomy and Prophylactic Salphingo-Oophorectomy in a BRCA1-Positive Breast Cancer Patient: A Case Report. J Breast Cancer 2008;11:218-22.

48. Choi MY, Lee JE, Kim SW, Lee SK, Hur SM, Kim S, et al. Incidental Detection of Ductal Carcinoma In Situ of the Breast from Bilateral Prophylactic Mastectomy of Asymptomatic BRCA2 Mutation Carrier: A Case Report. J Breast Cancer 2010;13:311-7.

49. Li FP, Fraumeni JF, Jr. Soft-tissue sarcomas, breast cancer, and other neoplasms. A familial syndrome? Ann Intern Med 1969;71:747-52.

50. Hwang SJ, Lozano G, Amos Cl, Strong LC. Germline p53 mutations in a cohort with childhood sarcoma: sex differences in cancer risk. Am J Hum Genet 2003;72:975-83.

51. Hwang SM, Lee ES, Shin SH, Kong SY. Genetic Counseling Can Influence the Course of a Suspected Familial Cancer Syndrome Patient: From a Case of Li-Fraumeni Like Syndrome with a Germline Mutation in the TP53 Gene. Korean J Lab Med 2008;28:493-7.

52. Lloyd KM, 2nd, Dennis M. Cowden's disease. A possible new symptom complex with multiple system involvement. Ann Intern Med 1963;58:13642.

53. Hong EJ, Kim HK, Cho YS, Ji JS, Kim CW, Kim CW, et al. A Case of Cowden Syndrome Associated with Breast Cancer and Thyroid Cancer. Korean J Gastrointest Endosc 2006;32:293-7.

54. Seo JA, Kim KJ, Shin EK, Lee EM, Moon W, Park MI, et al. A Case of Cowden's Disease Associated with Breast Cancer. Korean J Gastroenterol 2007:49:183-6.

55. Jung MH. Breast Cancer in Cowden Syndrome: A Case Report. J Korean Soc Radiol 2099;60:279-82.

56. Starink TM, van der Veen JP, Arwert F, de Waal LP, de Lange GG, Gille JJ, et al. The Cowden syndrome: a clinical and genetic study in 21 patients. Clin Genet 1986;29:222-33.

57. Hanssen AM, Fryns JP. Cowden syndrome. J Med Genet 1995;32:117-9.

58. Boardman LA, Thibodeau SN, Schaid DJ, Lindor NM, McDonnell SK, Burgart $L J$, et al. Increased risk for cancer in patients with the PeutzJeghers syndrome. Ann Intern Med 1998;128:896-9.

59. Yoon HJ, Cho DY, Im EH, Lee TH, Huh KC, Chung DJ, et al. A case of Peutz-Jeghers syndrome combined with metastatic adenocarcinoma with unknown primary origin. Korean J Med 2005;68:556-61.

60. Cohen PR, Kohn SR, Kurzrock R. Association of sebaceous gland tumors and internal malignancy: the Muir-Torre syndrome. Am J Med 1991;90:606-13.

61. Kim MS, Park OJ, Won CH, Chang SE, Lee MW, Choi JH, et al. A Case of Muir-Torre Syndrome: Extra-ocular Sebaceous Carcinoma in a Patient with Breast Cancer. Korean J Dermatol 2010;48:696-9.

62. Choi DH, Cho DY, Lee MH, Park HS, Haffty BG. Frequency of the CHEK2 1100 delC Mutation in Korean Women with Early Onset Breast Cancer. J Breast Cancer 2008;11:25-9. 
63. Rahman N, Seal S, Thompson D, Kelly P, Renwick A, Elliott A, et al. PALB2, which encodes a BRCA2-interacting protein, is a breast cancer susceptibility gene. Nat Genet 2007;39:165-7.

64. Tischkowitz M, Xia B. PALB2/FANCN: recombining cancer and Fanconi anemia. Cancer Res 2010;70:7353-9.

65. Wong MW, Nordfors C, Mossman D, Pecenpetelovska G, Avery-Kiejda KA, Talseth-Palmer B, et al. BRIP1, PALB2, and RAD51C mutation analysis reveals their relative importance as genetic susceptibility factors for breast cancer. Breast Cancer Res Treat 2011;127:853-9.

66. Kim JH, Choi DH, Cho DY, Ahn SH, Son BH, Haffty BG. PALB2 mutations 1592delT and 229delT are not present in Korean breast cancer patients negative for BRCA1 and BRCA2 mutations. Breast Cancer Res Treat 2010;122:303-6.
67. Seal $S$, Thompson D, Renwick $A$, Elliott $A$, Kelly $P$, Barfoot $R$, et al. Truncating mutations in the Fanconi anemia J gene BRIP1 are low-penetrance breast cancer susceptibility alleles. Nat Genet 2006;38:1239-41.

68. Zhang B, Beeghly-Fadiel A, Long J, Zheng W. Genetic variants associated with breast-cancer risk: comprehensive research synopsis, meta-analysis, and epidemiological evidence. Lancet Oncol 2011;12:477-88.

69. Kim KS, Kim SW, Lee MH, Ahn SH, Park SK, Society KBC. Practice patterns of surgeons for the management of hereditary breast cancer in Korea. J Breast Cancer 2008;11:95-101.

70. Kang E, Ahn SH, Noh WC, Noh DY, Jung Y, Kim LS, et al. The Change of Practice Patterns of the Hereditary Breast Cancer Management in Korea after the Korean Hereditary Breast Cancer Study. J Breast Cancer 2010; 13:418-30. 